\title{
NOTAS SOBRE A \\ POSSIBILIDADE DE UM \\ TRABALHO NO CARREFOUR
EPISTEMOLÓGICO ENTRE A \\ LINGUÍSTICA POPULAR E OS \\ ESTUDOS DO DISCURSO
}

\author{
NOTAS SOBRE LA POSIBILIDAD DE UN TRABAJO EN CARREFOUR EPISTEMOLÓGICO \\ ENTRE LINGÜÍSTICA POPULAR Y ESTUDIOS DEL DISCURSO
}

\author{
NOTES ABOUT THE POSSIBILITY OF A WORK IN EPISTEMOLOGICAL CARREFOUR \\ BETWEEN THE FOLK LINGUISTICS AND DISCOURSE STUDIES
}

Roberto Leiser Baronas*

Tamires Bonani Conti**

Universidade Federal de São Carlos

\begin{abstract}
RESUMO: Neste trabalho, fortemente apoiados na tese de Marie-Anne Paveau (2008) de que as abordagens da linguística popular/folk linguistics e das ciências da linguagem em geral são antieliminativas, isto é, as práticas linguísticas dos locutores profanos, os não-linguistas, mesmo aquelas de natureza mais prescritiva, são perfeitamente integráveis às análises linguísticas, propostas pelos linguistas, analisamos discursivamente de maneira não exaustiva um trabalho em linguística popular, que circula no contexto brasileiro no formato dicionário, a saber: o Dicionário Aurélia: a dicionária da língua afiada, publicado em 2006, pela Editora Bispa, de autoria dos jornalistas Vitor Angelo Scippe e Fred Libi.
\end{abstract}

PALAVRAS-CHAVE: Linguística popular. Análise do discurso. Dicionários.

RESUMEN: En este trabajo, respaldado firmemente por la tesis de Marie-Anne Paveau (2008) de que los enfoques de la lingüística popular/ folk linguistics y las ciencias del lenguaje en general son antidiscriminatorios, es decir, las prácticas lingüísticas de hablantes profanos, no lingüistas, incluso aquellas de naturaleza más prescriptiva, son perfectamente integrables con los análisis lingüísticos propuestos por los lingüistas, analizamos discursivamente uno trabajo no exhaustivo en lingüística popular que circula en el

\footnotetext{
${ }^{*}$ Doutor em Linguística e Língua portuguesa pela FCL/UNESP - Câmpus de Araraquara - SP e Professor no Departamento de Letras e no Programa de Pós-Graduação em Linguística da UFSCAR e Pesquisador do CNPq, nível 1 D. E mail: baronas@ufscar.br.

** Doutoranda no Programa de Pós-Graduação em Linguística da UFSCAR e Bolsista da Fundaça de Amparo à Pesquisa do Estadode SãoPaulo - FAPESP, processonúmero2018/05272-1. E mail: tamy_bonani@hotmail.com.
} 
contexto brasileño, a saber: El Diccionario Aurelia: El Diccionario de la Lengua afilada, publicado en 2006, por Editora Bispa, escrito por los periodistas Victor Ângelo Scippe y Fred Libi.

PALABRAS CLAVE: Lingüística popular. Análisis del discurso. Diccionarios.

ABSTRACT: This paper is strongly supported by Marie-Anne Paveau's (2008) thesis when she says that the approaches of folk linguistics and language sciences in general are anti-discriminatory, that is, the linguistic practices of the profane speakers, the nonlinguists, even those froma more prescriptive nature, are perfectly integrable to the linguistic analyzes proposed by the linguists. We discursively analyzed in a non-exhaustive way a study in popular linguistics that circulates in the Brazilian context, namely: The Aurelia Dictionary: The Dictionary of the Sharp Language, published in 2006, by Editora Bispa, authored by the journalists Victor Ângelo Scippe and Fred Libi.

KEYWORDS: Folk linguistics. Discourse analyzes. Dictionary.

\section{PRIMEIRAS PALAVRAS: UM POUCO SOBRE LINGUÍSTICA POPULAR E EPISTEMOLOGIA FOLK}

Se realizarmos uma pequena enquete em diferentes mídiuns, que circulam na web, constataremos sem muito esforço que as discussões propostas por não-linguistas sobre língua abundam. Por exemplo, o médico psiquiatra Jairo Bouer publicou no dia 07 de junho de 2019, em seu Blog na UOL, o artigo "Uso de pronomes pode revelar se a pessoa é avessa a relações sérias"; em 27 de julho passado, o jornalista Mario Sergio Conti publicou no jornal Folha de S. Paulo o artigo "Frase longa, vida breve: maior sentença de Proust, a permanência do passado no presente"; o jornalista Ruy Castro, em 07 de agosto último, publicou no jornal Folha de S. Paulo, o artigo "Pequeno glossário útil: para entender certas expressões que se tem aplicado a Bolsonaro". Os três textos mencionados, uma espécie de representação metonímica do que circula em diferentes mídiuns na web, mostram que as discussões sobre língua, não somente as de natureza mais prescritiva, cujo espaço desde sempre tem uma espécie de cadeira cativa nas mídias de uma maneira em geral, mas as que abordam a língua, nos seus mais variados aspectos, especialmente, as produzidas por nãolinguistas, são mais frequentes do que podíamos imaginar.

Diante dessa abundância de discussões sobre a língua, produzidas por não-linguistas, historicamente muitos de nós linguistas têm adotado uma postura supostamente crítica, frequentemente arrogante, buscando evidenciar com base nas mais diferentes ciências da linguagem, que tais trabalhos na grande maioria das vezes, carecem de fundamentação científica, descartando de imediato qualquer possibilidade de pertinência desses trabalhos ou mesmo de incorporação dos resultados obtidos pelos não-linguistas às nossas pesquisas.

"Não linguistas fazem linguística?" - pergunta-se a pesquisadora francesa Marie-Anne Paveau (2008) na parte inicial do título de artigo publicado na Revista Pratiques ${ }^{1}$. Este título-pergunta, especialmente na sua segunda parte, "uma abordagem antieliminativa das ideias populares", já nos antecipa um posicionamento teórico acerca do que se chama no contexto anglo-saxônico de folk linguistics, não sendo nenhum despautério que, para a autora, o saber (linguístico) folk, popular, profano ou leigo seja um saber prático e útil que ajuda os locutores de acordo com suas convicções a manterem e/ou transformarem a sociedade. Nesse sentido, a conclusão de Paveau vai na direção de que

[...] as informações geradas em práticas disciplinares folk são plenamente integráveis à análise linguística. A linguística folk possui, com efeito, uma validade de ordem prática e representacional, e deve, por isso, ser considerada pela 1 linguística científica como uma reserva de dados que nenhum linguista profissional consegue reunir com o auxílio dos métodos ditos 'científicos' (PAVEAU, 2008, p. 9, tradução nossa).

Embora possa parecer contraditório, Paveau (2008) assevera que a linguística folk está o tempo todo propondo uma das questões epistemológicas mais difíceis, especialmente, no domínio das ciências humanas e sociais: qual é a validade das teorias

${ }^{1}$ Este artigo foi publicado em francês na Revista Pratiques: linguistique, littérature e didactique, número 139/140, em dezembro de 2008. 
(pseudo)científicas? Segundo Paveau, existem poucos trabalhos sobre essa questão na França. No Brasil, uma simples olhadela no catálogo de Teses da CAPES (2019) mostra que o cenário não é muito diferente. A linguística folké, por um lado, majoritariamente, traduzida em termos de posição normativa ou de purismo e, por outro lado, a filosofia do espírito e a filosofia das ciências, sobretudo, nos Estados Unidos, propõem análises e respostas particularmente esclarecedoras sobre as folk sciences, em geral, ou sobre a linguística folk, em particular. Assim, veremos de modo bastante resumido como a autora usa tais respostas para validar teorias, que por falta de um melhor nome, poderíamos designar como espontâneas sobre a língua. Com efeito, qual é a validade das teorias folk? Para Paveau (2008), três respostas são possíveis: a posição eliminativa; uma posição intermediária e a posição integracionista.

a)

A posição eliminativa: o rigorismo da ciência dura

Se considerarmos a filosofia do espírito, a posição dita eliminativa ou do materialismo eliminativo está fundada sobre a tese que assevera que a compreensão dos estados mentais pelas teorias do senso comum está completamente errada. Com efeito, essas teorias, lastreadas no senso comum, não corresponderiam a nenhuma base científica. Tal compreensão pode se apoiar, por exemplo, sobre dados neurológicos. Dito de outro modo, não há base neural para certas teorias sobre a intencionalidade, ou mesmo sobre a própria consciência, noções que são as mais difíceis para naturalizar. No entendimento do filósofo Paul Churchland, por exemplo (2002 [1981]), as teorias folk são totalmente desprovidas de verdade e estão, além disso, no processo de serem substituídas ("eliminadas") por demonstrações irrefutáveis, concebidas pelas neurociências. O filósofo S. Laurence (2003) compartilha dessa mesma posição, pois considera que as teorias folk, em qualquer ciência, estão, na maior parte do tempo, erradas, constituindo-se num obstáculo para a construção dos verdadeiros saberes, os científicos. Ainda acrescenta Laurence que, a esse respeito, a linguística apresenta uma vulnerabilidade muito forte, já que se trata de uma teoria jovem com pouco mais de um século, se considerarmos o livro inaugural de Ferdinand de Saussure, o Curso de Linguística Geral - CLG, publicado em 1916.

Se deslocarmos tais questionamentos para os resultados da linguística folk, a teoria eliminativa dirá, então, que esse tipo de abordagem é uma teoria falsa, uma vez que se baseia em dados perceptivos, intuitivos, dotados de juízos de valor, mas sem nenhum componente cientificamente verificável; portanto, são saberes que devem ser totalmente ignorados em qualquer estudo da linguagem que se apresente como científico.

\section{b) Uma posição intermediária: o "realismo suave” de Daniel Dennett}

Uma posição intermediária é o que argumenta o filósofo Daniel Dennett (1990 [1987], 2002 [1991]), por ele chamada de "realismo suave". Essa posição intermediária está situada entre os dois extremos do "realismo de força industrial", de J. Fodor, e do materialismo eliminativo dos pesquisadores, o casal Churchland. Tal posição diz respeito à psicologia popular (folk psychology), assim descrita pelo autor:

[a]s pessoas são ainda menos previsíveis que o tempo, se tomadas frente às técnicas técnicas científicas dos meteorologistas e mesmo dos biólogos. Mas há outra perspectiva, que nos é conhecida desde a infância e que utilizamos sem esforço todos os dias, que parece maravilhosamente capaz de fornecer um sentido a todas essas complexidades. Chamamo-la comumente de psicologia popular. Ela é a perspectiva que invoca a família dos conceitos "mentalistas", como os de crença, desejo, conhecimento, medo, atenção, intenção, compreensão, sonho, imaginação, consciência de si, e assim por diante. (DENNETT, 1990 [1987], p. 17-18)

No entendimento de Dennett, o realismo suave pode ser assim sintetizado: o vocabulário e os conceitos "folk" são operacionais e, até mesmo, necessários para a vida social do homem, e as percepções espontâneas são estruturas (patterns) absolutamente fundamentais na vida humana: 
[h]á, nos assuntos humanos, estruturas que se impõem por elas mesmas de uma maneira que não é de modo algum inexorável, mas que têm grande força, absorvendo perturbações e variações psíquicas que poderíamos muito bem considerar como dadas ao mero acaso; são estruturas que caracterizaríamos em termos de crenças, desejos, intenções dos agentes racionais. (DENNETT, 1990 [1987], p. 42)

Ademais, para D. Dennett, por mais que se possa asseverar o contrário, a psicologia popular funciona (“a estratégia intencional funciona tão bem quanto possível"), mesmo que esse funcionamento não seja permanente. A psicologia popular é, com efeito, uma teoria imperfeita, incompleta e, consequentemente, não generalizável, mas, segundo Dennett, ela é uma teoria valiosa em vários pontos de seu funcionamento, dado que fornece uma espécie de guia para os indivíduos agirem.

Marie-Anne Paveau (2008) afirma que D. Dennett em seu trabalho propõe uma definição bastante completa da psicologia popular e, essa definição por conter, segundo a pesquisadora, um bom número de elementos, pode contribuir para a reflexão quanto à teoria linguística. Ela termina essa discussão sobre a posição intermediária de D. Dennett dizendo que, "[...] os dados da linguística folk são aceitáveis e integráveis à teoria linguística, porque fornecem descrições perceptivas e organizacionais exatas da linguagem, mas não podem servir de base para uma teoria geral da linguagem." (PAVEAU, 2008, p. 36).

Diferentemente das outras duas - a eliminativa e a intermediária - esta posição integracionista insiste sobre os saberes dos nãolinguistas, enquanto saberes legítimos e reconhecíveis como tais, podendo ser plenamente incorporados às análises linguistas dos profissionais deste campo. D. Preston e N. Niedzielski em sua síntese corroboram o perquirido por Paveau (2008): "Se o povo fala sobre a linguagem, ele deve, claro, saber (ou pelo menos acreditar que sabe) sobre isso" (PRESTON; NIEDZIELSKI, 1999, p. 10). A teoria linguística passa a ser compreendida a partir do mirante da sua operacionalidade e de sua verdade prática e não mais com base na lógica de uma teoria científica.

Esse tipo de entendimento é também a posição dos psicólogos sociais N. Llewellyn e A. Harrison (2006), em seus estudos sobre as percepç,ões das formas linguageiras e discursivas em documentos empresariais. Nesses estudos, os autores evidenciam que os participantes da enquete comprovaram uma competência linguística verdadeira, especialmente no que concerne ao reconhecimento dos empregos do pronome de primeira pessoa do plural, nós, e seus diferentes usos, ou mesmo na identificação da transformação passiva e da nominalização. Para Paveau (2008), com base em N. Llewellyn e A. Harrison, esse tipo de competência pode significar economia da metalinguagem e até mesmo do aprendizado das expressões detectadas. O "realismo ingênuo", por exemplo, que consiste em atribuir às entidades concretas do mundo fronteiras mais ou menos discretas, fazendo com que coincidam com os nomes que as designam, pode fazer saltar aos olhos um saber epilinguístico não consciente. Decorrentes desse saber epilinguístico são expressões correntes do cotidiano como "pau é pau" e "pedra é pedra".

Assim, ainda segundo a pesquisadora francesa, a noção de epilinguística é, sem dúvida, uma das mais importantes para se compreender como e por quê, a exemplo da psicologia popular, a linguística folk "funciona”. Segundo Paveau (2008, p. 37-8):

[...] a consciência epilinguística é uma instância que fornece dados 1 linguísticos da ordem da percepção. Se, numa perspectiva empírica, a linguística faz jus às dimensões experiencial e cultural da linguagem, ou seja, se o objeto da linguística integra os usos da língua pelos sujeitos sociais e cognitivos, então os dados perceptivos da linguística folk podem ser levados em conta como dados linguísticos, pura e simplesmente.

\section{O CÓDIGO LINGUAGEIRO DA AURÉLIA: O FUNCIONAMENTO DA INTERLÍGUA}

$\mathrm{O}$ anteriormente exposto nos mostra que Marie-Anne Paveau se inscreve numa epistemologia integracionista a partir da qual defende que as produções dos não-linguistas, os locutores profanos sobre a língua podem ser incorporadas aos estudos das ciências da linguagem. Nesse sentido, com o objetivo de testar a fecundidade da proposição de Paveau (2008), conforme já enunciado no 
resumo deste texto, mobilizamos discursivamente um trabalho, que a partir dos critérios estabelecidos por Paveau (2008) pode ser inscrito no campo da linguística popular, dado que é produzido por não-linguistas, toma a linguagem como objeto e circula no contexto brasileiro no formato dicionário, a saber: a Aurélia: a dicionária da língua afiada, publicado em 2006, pela Editora Bispa, de autoria dos jornalistas Victor Ângelo e Fred Libi.

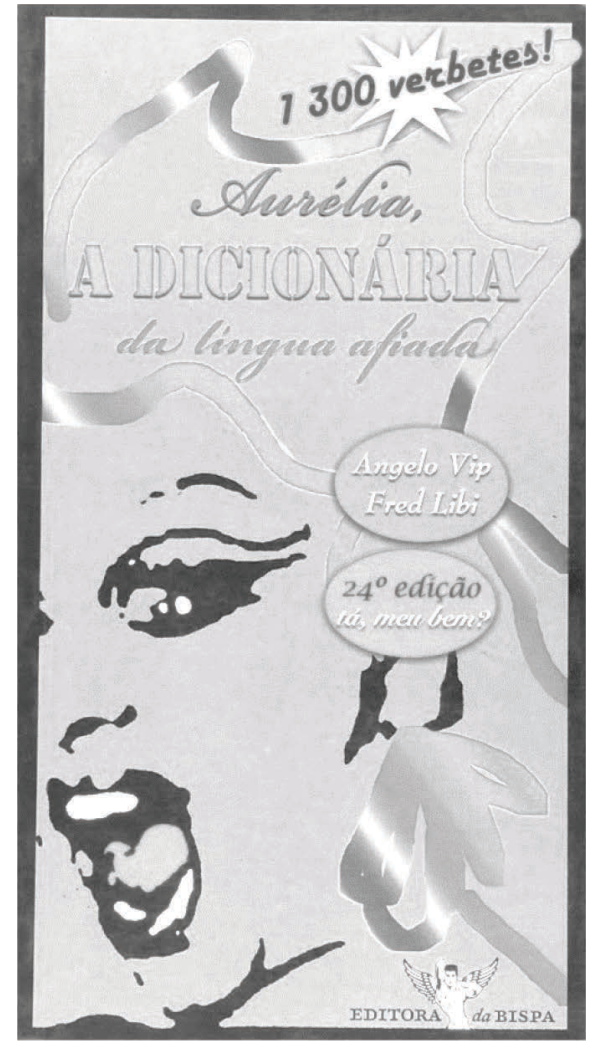

Figura 1: Capa da Dicionária Aurélia

Fonte: Google Images

A Aurélia: a dicionária da Língua Afiada é um bom exemplo de um trabalho de não-linguistas sobre a língua. Trata-se de um dicionário que não foi elaborado por lexicógrafos e sim por jornalistas. Objetivo dos dicionários tradicionais é catalogar as palavras usadas em uma determinada língua, apresentando, geralmente: definição, classificação gramatical, etimologia, divisão silábica, plural, sinônimos, antônimos etc. Com efeito, cumpre mostrar o quão os linguistas, por preconceito epistemológico, não se interessam por questões de linguagem que não sejam as produzidas por seus pares, uma vez que no âmbito das ciências da linguagem, embora exista uma grande quantidade de trabalhos que tomam os dicionários como objeto de estudo, há apenas dois trabalhos acadêmicos que lateralmente tomam a Dicionária Aurélia como objeto².

Trata-se do primeiro dicionário em Língua Portuguesa que reúne expressões e palavras utilizadas pela comunidade LGBTQ+, extraídas do Pajubá, cuja origem é africana e se apresenta como o idioma usado no universo gay em todo o Brasil. Resultado de ampla pesquisa dos autores, tendo o nome do livro como uma referência, talvez uma paródia do clássico dicionário Aurélio, o mais conhecido em Língua Portuguesa, o volume com 143 páginas contém 1.300 verbetes, todos descritos, na forma, como em um dicionário tradicional. Os verbetes que compõe "a Dicionária" foram colhidos em todas as regiões do Brasil, e ainda, segundo os autores, foram incluídas expressões e palavras de Portugal e de outros países do mundo que falam o português. O livro apresenta a classificação formal de classes de palavras utilizada pelos dicionários convencionais: substantivos, adjetivos, advérbios etc., assim como a origem geográfica dos vocábulos e expressões.

\footnotetext{
${ }^{2}$ Ver Peres (2017) e Lau (2015).
} 
Alguns exemplos de verbetes da Aurélia, assim como seus significados são:

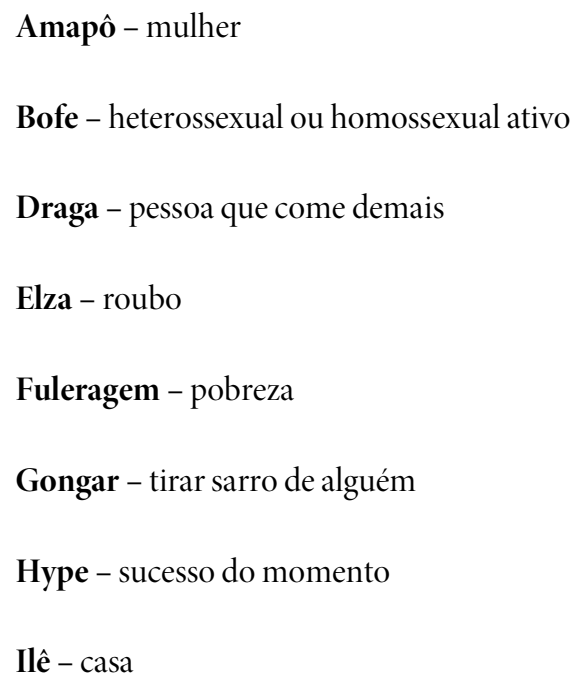

Kátia-cachaceira

Levar coió - ser xingado por alguém

Michê - garoto de programa

Neide - pessoa burra

Tais exemplos mostram que a teoria folk, que fundamenta esse tipo de produção linguística, é uma teoria prática ou uma teoria da prática. O saber profano é, na maior parte das vezes, um saber prático, um saber "útill" aos locutores para tentar mudar a sua sociedade. No caso em questão, os jornalistas, ao reunirem em um único documento com o status de um instrumento linguístico, palavras e expressões utilizadas pela comunidade LGBTQ+, advindas do Pajubá, além de procurar dar visibilidade às identidades dessa comunidade, dizendo das suas diferenças também linguísticas, buscam dirimir o preconceito e a discriminação existentes na nossa sociedade em relação a essa comunidade. Trata-se de um gesto prático em tom didático com natureza claramente política, de militância mesmo em favor de uma comunidade que historicamente vem sofrendo os mais variados tipos de preconceito e discriminação na nossa sociedade patriarcal, que tem extrema dificuldade em incorporar as diferenças.

De um mirante discursivo, especialmente, à luz das contribuições do discursivista francês Dominique Maingueneau (1995, 2002, 2005a, 2005b), a organização, a publicação e a circulação da dicionária Aurélia é um fato discursivo muito interessante, pois evidencia entre outras questões que não há um único uso ou usos da língua, mas posicionamentos dos locutores frente ao(s) uso(s) linguístico(s), isto é, o que se compreende como "a" língua, norma culta, idioma oficial, não é somente um código legitimado à disposição dos usuários, que a partir de suas necessidades, habilidades, competências ou mesmo criatividades comunicativas poderiam desdobrá-lo em distintos usos ou normas. A própria flexão de gênero do termo dicionário para dicionária, presente no título da obra de Vitor Angelo Scippe e Fred Libi, é um bom indício do posicionamento discursivo dos autores frente aos outros dicionários existentes no mercado. Com efeito, não se trata de a língua ser exterior e/ou posterior ao que se formula em termos do dizer, mas ela é constitutiva dos dizeres. Nesse sentido, no entendimento de Maingueneau (2002, p.23):

[...] em todo posicionamento, ao lado de investimentos em tais ou tais gêneros do interdiscurso, há também o investimento da interlíngua, por meio do qual uma obra se inscreve no espaço das práticas linguageiras e dos idiomas. Trata-se de um duplo investimento: entrada num espaço que se pretende ocupar e atribuição de valor. 
Num mesmo processo discursivo, a Aurélia busca entrar no espaço que os dicionários tradicionais ocupam na nossa sociedade, isto é, o dos instrumentos linguísticos autorizados e legitimados a dizer sobre questões de língua e, por extensão, de nacionalidade, bem como busca capitalizar o valor simbólico que tais instrumentos possuem na nossa sociedade. De um só golpe, a Aurélia busca entrar no rol dos dicionários e também amealhar o valor que tais instrumentos têm na nossa sociedade.

A Aurélia mostra então que as obras possuem línguas próprias, ou melhor, que as textualizações, os discursos têm as suas próprias línguas, não em termos de morfologia, léxico ou sintaxe, que são únicos para uma determinada língua, mas destacando ou silenciando certos sentidos, autorizando ou não certas leituras, interpretações, determinadas co-enunciações e co-enunciadores e, especialmente, evidenciando a existência de um tipo particular de corporeidade linguística que advêm dessas próprias línguas. Com efeito, o verbete Amapô, por exemplo, presente na Aurélia, não é apenas outro nome para o verbete mulher como num dicionário tradicional, que a situa basicamente ou na ordem do biológico ou na ordem de uma única estrutura familiar ${ }^{3}$, mas a possibilidade mesmo de os locutores, que pertencem a comunidade LGBTQ+, se posicionarem criticamente frente à língua, bem como frente à relação unívoca, que os dicionários tradicionais, por meio da catalogação de palavras e de alguns de seus sentidos, estabelecem com o mundo, interferindo no como são conferidas as significações para as coisas que existem no mundo. Dito de outro modo, a Aurélia mostra que para além de ser um monumento a língua, os dicionários são produtos tecnológicos construídos pelo homem em determinado momento histórico e social, cuja objetividade e neutralidade das definições são efeitos ideológicos, que buscam a todo o momento silenciar os sentidos outros que não os autorizados nos/pelos dicionários.

Maingueneau chama a atenção para o fato de que os textos de natureza literária parecem ter uma corporeidade linguística bastante propícia à constatação desse investimento da interlíngua. "O trabalho de escrita consiste sempre em transformar nossa própria língua em língua estrangeira, em convocar outra língua na língua, língua outra, língua do outro, outra língua” (MAINGUENEAU, 2005b, p. 180). Nesse sentido, um escritor em seu trabalho "não é [simplesmente] confrontado com a língua, mas com uma interação de línguas e de usos". Há aqui um tipo particular de diálogo, o do escritor com “outras línguas”. O que ele diz é produzido sempre numa dada conjuntura histórica e social em que distintas relações “[...] entre as variedades de uma mesma língua, mas também entre essa língua e as outras, passadas e contemporâneas" (MAINGUENEAU, 2005b, p. 180). Ao retomar expressões da língua Pajubá, falada por sujeitos africanos de diversas nacionalidades, a Aurélia não só retoma uma memória discursiva de resistência dessa língua, atualizando-a, mas a coloca na condição de uma língua que identifica a comunidade LGBTQ+. Desse modo, o escritor trabalha uma língua numa língua, numa espécie de arqueologia do linguístico, escavando, delineando "um hiato irredutível com relação à língua materna”, percorrendo entre as margens, as perilínguas, fronteiras imaginárias, demarcáveis somente para cumprir determinadas funções: que as línguas têm origem, têm unidade e são uma propriedade de todos

A Aurélia evidencia também que mesmo obras como um dicionário, que, por um lado, se apresentam como um objeto que visa a instrumentalizar uma língua, colocando-lhe uma espécie de espartilho de sentidos (im)possíveis, e, por outro, como um dos

\footnotetext{
${ }^{3}$ Numa breve visita em um dicionário tradicional como o Dicionário Eletrônico Michaelis [2015], é possível constatar que o verbete mulher embora possua 11 definições, elas estão apensas basicamente a dois sentidos: na ordem do biológico ou na ordem de uma única estrutura familiar. "Mulher: substantivo feminino: 1 indivíduo do sexo feminino, considerado do ponto de vista das características biológicas, do aspecto ou forma corporal, como tipo representativo de determinada região geográfica, época etc. $\langle m$. negra $\langle m$. de seios pequenos $\triangleleft m$. carioca $\langle m$. das cavernas 1.1 aquela que tem sua fisiologia e sua vida genital percebidas como essência do ser humano feminino em sua evolução 1.1.1 na puberdade, com a chegada dos ciclos menstruais, quando ovula e pode conceber; entre menina e moça «somente em seu primeiro mênstruo sentiu-se m., sua vital e intima diferença〉 1.1.1.1 na fase núbil, pronta para casar-se; moça, mocinha ‘típico patriarca nordestino, observa as m. de sua prole: proveitosos contratos adviriam! 1.1.2 quando deixa de ser virgem ‘tornou-se m. bem cedinho com seu primeiro namorado 2 o ser humano feminino, considerado 2.1 em conjunto, ideal ou concretamente «e Deus criou a m.> 2.2 por sua experiência inerente e cultural «disse-lhe, como m., que dificilmente ela ascenderia à gerência 3 descendente do sexo feminino; filha «- Já nasceu? - Homem ou m.? 4 m.q. mulher-feita «tem uma filha que já é m., vive fora do país há anos` 5 (sXIV) companheira conjugal; esposa «sua m. não poderá acompanhá-lo devido a compromissos profissionais 5.1 companheira, ger. constante; a outra; amante, concubina 〈diz a lenda que marinheiros têm uma m. em cada porto 6 p.ext. fêmea humana como parceira sexual «mudou de vida, deixou as noitadas e as m. 6.1 namorada 〈apresentou-lhes, envaidecido, sua m. atual 7 fig. na tradição, como indivíduo e/ou coletivamente, representação de um ser 7.1 fig. cuja principal função é cuidar da família, dos afazeres domésticos etc. «existe a m. que sonha tornar-se 'rainha do lar' 7.2 fig. fraco fisicamente, sem defesa; apelidado de 'o sexo frágil' $\prec$ que pode a m. contra um homem em sua fúria? 7.2.1 fig. idealmente belo; o chamado 'belo sexo' «vive a m. sem espelho? 7.2.2 fig. sensível, delicado, afetivo, intuitivo «como m., chora em todo filme romântico 7.2.3 fig.; pej. insensato, superficial, volúvel «aquela m. troca tanto de marido quanto de cor do cabelo 7.2 .4 fig.; pej. intrigante e/ou sedutor há m. que, vaidosas, fazem das dissensões entre os pares quase que um esporte 7.3 infrm. cuja presença censura a linguagem masculina (esp. quanto ao uso de expressões de baixo calão) 〈moderou-se quando percebeu que o caixa era uma m.> 8 infrm. pessoa indeterminada 〈uma $m$. deu-lhe a informação por opôs. a senhora e dama 18.1 p.ext.; obsl. serviçal ou empregada que trabalha para alguém ou em determinada tarefa ‘trabalhava com o conselheiro uma m. muito dedicada 9 us. como interlocutório pessoal «- Então, m., qual é a solução? 10 pej. homem efeminado, que lembra uma mulher, esp. quanto aos hábitos, gostos, trejeitos considerados tipicamente femininos 11 homem homossexual, ou que é o parceiro passivo numa relação sexual com outro homem”.
} 
símbolos da nossa nacionalidade, uma vez que, ao instrumentalizarem uma língua, legitimam esse idioma como o único possível perante uma comunidade linguística é também passível do investimento da interlíngua.

Os escritores da Aurélia, ao escavarem um hiato na língua materna, a partir do engendramento de um tipo particular de instrumento linguístico, um dicionário da comunidade LGBTQ+, advindo da língua própria desta comunidade, o Pajubá, mostram que o que está nas bordas marginalizadas dessa língua materna, está nessa condição de subalternidade não por uma ordem natural das coisas, mas pela imposição de certos sentidos em detrimento de outros. Em suma, o que eles mostram com a Aurélia é que os sentidos, por mais que pareçam colados às palavras, são sempre o resultado de uma renhida luta entre interlocutores - co-enunciadores: sujeitos históricos, heterogêneos, constitutivamente dialógicos, que buscam a todo momento textualizar os seus discursos em certos códigos linguageiros. Desse modo, "[...] o uso da língua que a obra implica se apresenta como a maneira pela qual se tem de enunciar, por ser esta a única maneira compatível com o universo que ela instaura” (MAINGUENEAU, 2005a, p. 182).

Para concluir essa breve análise discursiva, diremos que mais do que uma simples tecnologia que busca instrumentalizar uma determinada variedade linguística, mostrando a sua condição de subalternidade em relação não só ao que seria a norma padrão ou a outras variedades de prestígio, ou um símbolo de nacionalidade, a Aurélia se constitui num discurso de militância sobre a língua da comunidade LGBTQ+. Com efeito, no que concerne à discursividade da Aurélia, é possível asseverar que a obra institui um modo de dizer que insta a manifestação de uma interlíngua própria (um código linguageiro específico, um estilo da comunidade LGBTQ+), todavia, sem impor um padrão a ser seguido, como o faz a norma culta, por exemplo e, nem se apresentar como uma língua de madeira, hermética, inacessível para os que não fazem parte da comunidade. Para além e aquém disso, a Aurélia incita essa modelização do padrão a se desarranjar, propondo em seu lugar a possibilidade de inauguração de um mundo que se dá a ver no próprio ato de inauguração, ou seja, a pertinência e mesmo a necessidade de se dar a ver do modo como se dá a ver. Ademais, no que concerne estritamente ao linguístico, a Aurélia não tem relação natural com qualquer uso linguístico; mesmo quando a obra parece empregar uma língua, que, no nosso imaginário puritano, possa ser considerada "chula", "pejorativa", existe sempre o confronto com a alteridade da linguagem, vinculada a um posicionamento determinado no campo dos instrumentos linguísticos e, consequentemente, da própria língua.

Propomos aqui apenas uma primeira aproximação discursiva da Aurélia, com o objetivo de refletir sobre seu código linguageiro e, por extensão, sobre o conceito de interlíngua proposto alhures por Maingueneau para pensar o texto literário. Nossa análise mostrou que o código linguageiro da Aurélia é condicionado pela interação dos registros e variantes das línguas acessíveis em uma dada conjuntura, a interlíngua. E que esse código linguageiro é a maneira encontrada de enunciar e nenhuma outra para construir o mundo que a obra constrói: o discurso de militância sobre a língua e a identidade da comunidade LGBTQ+.

\section{NOTAS BREVES DE ENCERRAMENTO}

Marie-Anne Paveau (2008, p. 39) diz que “[...] a enorme variedade das posições discursivas folk, das práticas correspondentes e dos dados assim recolhidos, assim como a fragilidade científica de um bom número de observaç,ões científicas (geradas de posições subjetivas, que são frequentemente idioletais)" devem, sem dúvida, fazer com que o objeto da linguística seja repensado. Assim, segundo a autora: "[...] é quase irracional que se continue a definir o objeto da linguística como Saussure o fez em 1916, apostando numa sistematicidade asséptica da língua; tal objeto foi profundamente afetado pelos saberes de que foi alvo e os saberes folk fazem parte dele.” Também não é menos irracional que, após Saussure, a linguística entrou numa espécie de luta entre duas vias contraditórias - logicismo versus sociologismo - que já dura bem mais de meio século, como já apontaram brilhantemente Pêcheux e Gadet (1999) no artigo "Há uma via para a linguística fora logicismo e do sociologismo? A questão que se põe hoje, passados praticamente dois decênios do século XXI, não é mais a do ou isto ou aquilo, para brincar seriamente com o poema de Cecília Meireles, mas a da integração de saberes.

\footnotetext{
${ }^{4}$ A tradução brasileira deste artigo, elaborada pela Profa. Eni Orlandi, foi publicada na Revista Escritos, número 03, cujo título é Discurso e política em janeiro de 1999 .
} 
Nesse sentido, Paveau propõe uma descrição renovada, convincente e, sobretudo, cientificamente eficaz do objeto da linguística, adotando uma posição antieliminativa, que integre a escala dos saberes linguísticos, ou seja, do saber científico mais "duro" ao saber folk mais "suave" (PAVEAU, 2008, p. 40). Cumpre destacar que essa incorporação dos saberes folk aos saberes científicos sobre a linguagem não significa se render a uma espécie de terraplanismo linguístico de ocasião, mas fazer com que esses saberes folk possam ranger, gritar no sentido em que testemunha Foucault, em relação ao pensamento de Nietzsche, cujo único sinal de reconhecimento que se pode ter é "deformá-lo, fazê-lo ranger e gritar". Assim também é preciso proceder em relação aos saberes folk acerca da linguagem.

\section{REFERÊNCIAS}

BOUER, J. Uso de pronomes pode revelar se a pessoa é avessa a relações sérias. UOL, 7 jun. 2019. Disponível em: https://doutorjairo.blogosfera.uol.com.br/2019/06/07/uso-de-pronomes-pode-revelar-se-a-pessoa-e-avessa-a-relacoes-serias. Acesso em: 10 set. 2019.

CAPES. Catálogo de teses. 2019. Disponível em: https://catalogodeteses.capes.gov.br/catalogo-teses/\#!/. Acesso em: 10 set. 2019.

CASTRO, R. Pequeno glossário útil: para entender certas expressões que se tem aplicado a Bolsonaro. Folha de S. Paulo, São Paulo, 7 ago. 2019. Disponível em: https://wwwl.folha.uol.com.br/colunas/ruycastro/2019/08/pequeno-glossario-util.shtml. Acesso em: 10 set. 2019.

CONTI, M. S. Frase longa, vida breve: maior sentença de Proust, a permanência do passado. Folha de S. Paulo, São Paulo, 27 jul. 2019. Disponível em: https://www1.folha.uol.com.br/colunas/mariosergioconti/2019/07/frase-longa-vida-breve.shtml. Acesso em: 10 set. 2019.

CHURCHLAND, P. Le matérialisme éliminativiste et les attitudes propositionnelles. In: FISETTE, D.; POIRIER, P. (org.). Philosophie de l'esprit. Psychologie du sens commun et sciences de l'esprit. Paris: Vrin, 2002 [1981]. p. 117-151.

DENNETT, D.C. La stratégie de l’interprète. Le sens commun et l'univers quotidien. Trad. P. Engel. Paris: Gallimard, 1990 [1987].

DENNETT, D.C. De l'existence des patterns [Realpatterns]. In: FISETTE, D.; POIRIER, P. (org.). Philosophie de l'esprit. Psychologie du sens commun et sciences de l'esprit. Paris: Vrin, 2002 [1981]. p. 153-193.

LAU, H. D. A (des)informação do bajubá: fatores da linguagem da comunidade LGBT para a sociedade. Temática, v.11, n.2, fev. 2015. Disponível em: http://periodicos.ufpb.br/ojs2/index.php/tematica. Acesso em: 10 set. 2019.

LAURENCE, S. Is Linguistics a branch of Psychology?. In: BARBER, A. (org.). The Epistemology of Language. Oxford: OUP, 2003. p. $69-106$

LLEWELLYN, N.; HARRISON, A. Resisting corporate communications: insights into folk linguistics. In: Human Relations, v.5, n.4, p. $567-596,2006$.

MAINGUENEAU, D. Gênese dos discursos. Trad. Sírio Possenti. Curitiba: Criar, 2005a [1984].

MAINGUENEAU, D. Ethos, cenografia e incorporação. In: AMOSSY, R. (org.). Imagens de si no discurso. São Paulo: Contexto, 2005 b [1999]. p. 69-92. 
MAINGUENEAU, D. Discours, intertextualité, interlangue. Champs du signe, n. 13/14, p.197-210, 2002. [mimeo, sem paginação].

MAINGUENEAU, D. O contexto da obra literária - enunciação, escritor, sociedade. Trad. Marina Appenzeller. São Paulo: Martins Fontes, 1995 [1993].

MODERNO DICIONÁRIO DA LÍNGUA PORTUGUESA. [2015]. Disponível em: http:// michaelis.uol.com.br/moderno/portugues/index.php. Acesso em: 22 nov. 2019.

PAVEAU, M.-A. Les non-linguistes font-ils de la linguistique?. Pratiques [En ligne], p.139-140, 2008, mis en ligne le 15 décembre 2008. Disponível em: https://journals.openedition.org/pratiques/1200. Acesso em 19 abr. 2019.

PÊCHEUX. M; GADET, F. Há uma via para a linguística fora logicismo e do sociologismo?. Revista Escritos, , n. 3, paginação irregular, jan. 1999. Disponível em: https://www.labeurb.unicamp.br/portal/pages/pdf/escritos/Escritos3.pdf. Acesso em: 10 set. 2019.

PERES, N. da C. Uso e apropriação do Pajubá na construção de uma identidade LGBT. 2017. Trabalho de Conclusão de Curso (Graduação em Letras) - Universidade Federal do Pampa, Campus de Jaguarão, 2017. Disponível em: http://dspace.unipampa.edu.br/bitstream/riu/2343/1/NathaliadaCruzPeres2017.pdf. Acesso em: 10 set. 2019.

PRESTON, D.; NIEDZIELSKI, N. Folk Linguistics. With a new preface. Berlin, New York: Mouton De Gruyter, 2003 [2000].

SCIPPE, V. A.; LIBI, F. Dicionário Aurélia: a dicionária da língua afiada. São Paulo: Editora Bispa, 2006.

\section{(๑) $\circledast \circledast$}

